\title{
Transport Kinetics, Selective Inhibition, and Successful Prediction of In Vivo Inhibition of Rat Hepatic Organic Anion Transporting Polypeptides ${ }^{\mathbb{}}$
}

\author{
Kazuya Ishida, Mohammed Ullah, Beáta Tóth, Viktoria Juhasz, and Jashvant D. Unadkat \\ Department of Pharmaceutics, University of Washington, Seattle, Washington (K.I., J.D.U.); Cellular Transport Group, \\ Pharmaceutical Sciences, Roche Innovation Centre Basel, F. Hoffmann-La Roche Ltd., Basel, Switzerland (M.U.); and SOLVO \\ Biotechnology, Budaörs, Hungary (B.T., V.J.)
}

Received January 31, 2018; accepted June 7, 2018

\section{ABSTRACT}

For successful in vitro-to-in vivo extrapolation of hepatic drug uptake and drug-drug interactions (DDI), it is important to characterize the kinetic properties of the individual transporters involved, their fraction (ft) contribution to hepatic uptake, and their selective inhibitors. Here, we characterized the in vitro transport kinetics of two model drugs, rosuvastatin (RSV) and olmesartan acid (OLM), by rat hepatic organic anion transporting polypeptides (Oatp1a1, 1a4, and 1b2) and identified selective inhibitors of these transporters. $\left[{ }^{3} \mathrm{H}\right]-\mathrm{RSV}$ was transported by Oatp1a1, 1a4, and 1b2, and their Michaelis-Menten constant $\left(K_{m}\right)$ values were estimated to be $9.61,67.2$, and $28.1 \mu \mathrm{M}$, respectively. In contrast, $\left[{ }^{3} \mathrm{H}\right]$-OLM was transported by only Oatp1b2 $\left(K_{\mathrm{m}}: 72.8 \mu \mathrm{M}\right)$. Digoxin $\left(\mathrm{IC}_{50}: 0.107 \mu \mathrm{M}\right)$ and rifamycin SV $\left(\mathrm{IC}_{50}: 0.140\right.$ and
$0.088 \mu \mathrm{M}$ for RSV and OLM, respectively) were potent and selective inhibitors of Oatp1a4 and 1b2, respectively, and glyburide (100 $\mu \mathrm{M})$ completely inhibited all three rat hepatic Oatps. These inhibitors can therefore be used alone and in combination to determine the contribution of each Oatp to hepatic influx. In addition, the magnitude of in vivo inhibition of sinusoidal uptake clearance of RSV by rifampin was well predicted using rifampin IC $_{50}$ profiles for each Oatps and RSV $\mathrm{ft}$ by each Oatp. This is the first report to 1) detail the transport kinetics of RSV and OLM by rat hepatic Oatps, 2) identify selective inhibitor concentrations of rat Oatps, and 3) demonstrate successful prediction of the magnitude of transporter-mediated in vivo DDI from $\mathrm{IC}_{50}$ profiles of an inhibitor and $\mathrm{ft}$ of a drug by each transporter.

\section{Introduction}

The rat is commonly used as a preclinical species in drug development and pharmacokinetics and toxicity studies. In addition, the rat is often used when conducting proof of concept or mechanistic pharmacokinetic studies. For example, we have recently shown that the in vivo hepatobiliary clearances and hepatic concentrations of rosuvastatin (RSV) in rats can be predicted using transporter-expressing cells and sandwich-cultured rat hepatocytes (Ishida et al., 2018). However, to correctly interpret and extrapolate the hepatic clearance obtained from in vitro systems to in vivo, it is important to have detailed characterization of transport kinetics (e.g., the Michaelis-Menten constant, $K_{\mathrm{m}}$ ) of rat hepatic organic anion transporting polypeptides (Oatp1a1, 1a4, and 1b2) and their relative contribution to hepatic drug uptake using methods employing selective inhibition or in vitro-to-in vivo scaling of transporter-mediated clearance using quantitative proteomics.

Although this approach is well established when determining the cytochrome $\mathrm{P} 450$-mediated fraction metabolized, due to the lack of selective inhibitors of transporters this approach has had limited success

This work was supported by a Postdoctoral Fellowship from F. Hoffmann-La Roche Ltd. (to K.I.).

https://doi.org/10.1124/dmd.118.080770.

SThis article has supplemental material available at dmd.aspetjournals.org. in determining the fraction transported (ft) by hepatic transporters. To this end, we characterized rat hepatic Oatp transport kinetics of two model drugs-RSV and olmesartan acid (OLM) — and identified selective inhibitors of rat Oatps that can be used to quantify the contribution of each rat hepatic Oatp toward overall Oatp-mediated hepatic uptake. In addition, we assessed whether the in vivo inhibition of RSV hepatic uptake clearance by rifampin (a known inhibitor of rat Oatp), determined in our positron emission tomography (PET) imaging study (He et al., 2014), could be predicted from in vitro Oatp inhibition profiles - the halfmaximal inhibitory concentrations $\left(\mathrm{IC}_{50}\right)$ profiles — of rifampin and the $\mathrm{ft}$ of RSV by the various Oatps estimated using quantitative proteomics.

\section{Materials and Methods}

Materials. RSV was purchased from Cayman Chemicals (Ann Arbor, MI). OLM was kindly provided from Daiichi-Sankyo (Tokyo, Japan). [ $\left.{ }^{3} \mathrm{H}\right]-\mathrm{RSV}$ sodium salt (20 mCi/mmol, radiochemical purity $99 \%),\left[{ }^{3} \mathrm{H}\right]-\mathrm{OLM}(10 \mathrm{mCi} / \mathrm{mmol}$, radiochemical purity $99 \%),\left[{ }^{3} \mathrm{H}\right]$-estradiol $17 \beta$-d-glucuronide $(\mathrm{E} 17 \beta \mathrm{G})(50 \mathrm{mCi} / \mathrm{mmol}$, radiochemical purity $99 \%)$, and $\left[{ }^{3} \mathrm{H}\right]$-taurocholic acid (TCA) $(10 \mathrm{mCi} / \mathrm{mmol}$, radiochemical purity 99\%) were purchased from American Radiolabeled Chemicals (St. Louis, MO). Rifampin, rifamycin SV sodium salt, ibuprofen, indomethacin, sulfobromophthalein (BSP) disodium salt, quinidine hydrochloride monohydrate, quinine hydrochloride dihydrate, glycyrrhizic acid, enalapril, and fexofenadine hydrochloride were purchased from Sigma-Aldrich (St. Louis, MO). Celiprolol hydrochloride and cyclosporin A were purchased from Toronto Research Chemicals

ABBREVIATIONS: BSP, sulfobromophthalein; $\mathrm{CHO}$, Chinese hamster ovary cells; $\mathrm{CL}$, clearance; DDI, drug-drug interactions; $\mathrm{E} 17 \beta \mathrm{G}$, estradiol $17 \beta$-D-glucuronide; ft, fraction of drug transported; HEK293, human embryonic kidney 293 cells; $K_{\mathrm{d}}$, diffusion rate constant; KH, Krebs-Henseleit; $K_{\mathrm{m}}$, Michaelis-Menten constant; Ntcp, $\mathrm{Na}^{+}$-taurocholate cotransporting polypeptide; OATP/Oatp, organic anion transporting polypeptide; PET, positron emission tomography; RSV, rosuvastatin; TCA, taurocholic acid; $V_{\max }$, maximum velocity of the uptake. 
(Toronto, ON, Canada). Digoxin was purchased from Tokyo Kasei America (Portland, OR). Glyburide was purchased from Calbiochem (La Jolla, CA). All other chemicals were of reagent or analytic grade and were purchased from other commercial suppliers.

RSV and OLM Uptake into Ntcp- and Oatp-Expressing Cells. Chinese hamster ovary- $\mathrm{Na}^{+}$-taurocholate cotransporting polypeptide (CHO-Ntcp), CHO-Oatp1a1, human embryonic kidney 293 (HEK293)-Oatp1a4, HEK293-Oatp1b2, and their corresponding mock-transfected cells were a gift from SOLVO Biotechnology (Budaörs, Hungary). CHO-Ntcp, CHO-Oatp1a1, and CHO-mock cells, grown in $75 \mathrm{~cm}^{2}$ flasks, were harvested using trypsin and were plated at a density of $0.5 \times 10^{6}$ cells/well in 24-well plates. These cells were incubated with $5 \mathrm{mM}$ sodium butyrate for approximately 24 hours before conducting the transport experiments. HEK293-Oatp1a4, HEK293-Oatp1b2, and HEK293-mock cells, grown in $75 \mathrm{~cm}^{2}$ flask with $3 \mu \mathrm{g} / \mathrm{ml}$ puromycin, were harvested using trypsin and plated at a density of $0.5 \times 10^{6}$ cells/well in 24-well poly-D-lysine coated plates. These cells were also incubated with $3 \mu \mathrm{g} / \mathrm{ml}$ of puromycin for 24 hours before conducting the transport experiments.

The cells were washed 3 times with prewarmed Krebs-Henseleit $(\mathrm{KH})$ buffer then preincubated (at $37^{\circ} \mathrm{C}$ for 10 minutes) with the $\mathrm{KH}$ buffer in the absence or presence of the chosen inhibitor. After preincubation, the cells were incubated (at $37^{\circ} \mathrm{C}$ for $5-120$ seconds) with $500 \mu \mathrm{l}$ of $0.01-1000 \mu \mathrm{M}$ RSV (containing $0.2 \mu \mathrm{Ci} /$ well $\left[{ }^{3} \mathrm{H}\right]$-RSV) or OLM (containing $0.2 \mu \mathrm{Ci} /$ well $\left[{ }^{3} \mathrm{H}\right]-\mathrm{OLM}$ ) with or without the chosen inhibitor. The $\mathrm{KH}$ buffer containing the drug was aspirated, and the cells were washed 3 times with ice-cold $\mathrm{KH}$ buffer, and then $1 \mathrm{ml}$ of $2 \%$ SDS was added to lyse the cells.

The total radioactivity in the samples was measured using a liquid scintillation counter (Perkin Elmer, Waltham, MA). The total protein concentration of cell lysate was measured with the Pierce BCA Protein Assay Kit (Pierce Biotechnology, Rockford, IL), according to the manufacturer's instructions. As a positive control, the uptake of TCA (for Ntcp, $0.5 \mu \mathrm{M}$ TCA containing $0.2 \mu \mathrm{Ci} /$ well $\left.\left[{ }^{3} \mathrm{H}\right]-\mathrm{TCA}\right)$ in the presence and absence of the extracellular $\mathrm{Na}^{+}$or the uptake of $\mathrm{E} 17 \beta \mathrm{G}$ (for Oatp, $0.5 \mu \mathrm{M} \mathrm{E} 17 \beta \mathrm{G}$ containing $0.2 \mu \mathrm{Ci} /$ well $\left.\left[{ }^{3} \mathrm{H}\right]-\mathrm{E} 17 \beta \mathrm{G}\right)$ in the absence and presence of $100 \mu \mathrm{M}$ rifamycin $\mathrm{SV}$ was also determined.

Estimation of $\boldsymbol{K}_{\mathrm{m}}$ and $\boldsymbol{V}_{\max }$ of RSV and OLM. The $K_{\mathrm{m}}$, the maximum velocity $\left(V_{\max }\right)$, and the diffusion rate constant $\left(K_{\mathrm{d}}\right)$ were estimated using the nonlinear regression package Phoenix (Certara, Princeton, NJ). The following equations were simultaneously fitted to the data (Malo and Berteloot, 1991; Chenu and Berteloot, 1993; Endres et al., 2009):

$$
\begin{aligned}
v_{\text {Oatp }} & =\frac{V_{\text {max }} \cdot T \cdot\left(S_{\text {cold }}+T\right)^{H-1}}{K_{\mathrm{m}}^{H}+\left(S_{\text {cold }}+T\right)^{H}}+K_{\mathrm{d}} \cdot T \\
v_{\text {mock }} & =K_{\mathrm{d}} \cdot T
\end{aligned}
$$

where $v_{\text {Oatp }}$ and $v_{\text {mock }}$ are the uptake rate of the drug into Oatp-expressing cells and mock-transfected cells, respectively. $S_{\text {cold }}$ and $T$ are the concentration of unlabeled and labeled drug, respectively. $H$ is the Hill coefficient.

Estimation of $\mathbf{I C}_{\mathbf{5 0}}$ of Inhibitors. The $\mathrm{IC}_{50}$ of several drugs toward RSV or OLM uptake was estimated using the nonlinear regression package Phoenix (Certara). The following equations were simultaneously fitted to the data:

$$
\begin{aligned}
& \text { Uptake }_{\text {Oatp }}(\% \text { of Max })=\operatorname{Min}+\frac{\text { Max }- \text { Min }}{1+\left([I] / \mathrm{IC}_{50}\right)^{H}} \\
& \text { Uptake }_{\text {mock }}(\% \text { of Max })=\text { Min }
\end{aligned}
$$

where Max and Min are the maximum (fixed at 100\%, i.e., uptake in the absence of the inhibitor) and minimum uptake (uptake in mock cells or when the inhibitor concentration greatly exceeds $\mathrm{IC}_{50}$, expressed as $\%$ of Max) of the drug, respectively. $[I]$ and $H$ are the inhibitor concentration and Hill coefficient, respectively.

Prediction of the Inhibitory Effect of Rifampin on In Vivo Sinusoidal Uptake Clearance of RSV in the Rat Liver. The in vivo sinusoidal uptake clearance $(\mathrm{CL})$ of RSV in the presence of rifampin $\left(\mathrm{CL}_{\mathrm{s} \text {, uptake }}^{\mathrm{Rif}}\right)$ at the steady-state plasma rifampin concentration observed in our PET imaging study $(9.4 \mu \mathrm{M})$ was estimated as follows:

$$
\mathrm{CL}_{\mathrm{s}, \text { uptake }}^{\mathrm{Rif}(+)}=\sum\left(\mathrm{CL}_{\text {uptake, } i}^{\mathrm{Rif}(-)} \cdot \% \text { Remaining activity }\right)+\mathrm{CL}_{\text {passive }}^{\mathrm{HEK293}}
$$

where $\mathrm{CL}_{\text {uptake, }}^{\mathrm{Rif}(-)}{ }_{i}$ is the in vivo predicted sinusoidal uptake clearance of RSV in the rat liver by each Oatp. That is, the predicted in vivo uptake clearance was obtained by the summation of the intrinsic in vitro uptake clearance of RSV (by Oatp1a1, 1a4, and 1b2) scaled up to in vivo value using the abundance of each Oatp in the Oatp-expressing cell line and in vivo (in the rat liver) (data obtained from Wang et al., 2015; Ishida et al., 2018). $\mathrm{CL}_{\text {passive }}^{\mathrm{HEK}}$ is the passive diffusion clearance of RSV estimated from HEK293-mock cells (the mean $K_{\mathrm{d}}$ value in the present study). The "\% Remaining activity" of each Oatp in the presence of $9.4 \mu \mathrm{M}$ rifampin was calculated from the $\mathrm{IC}_{50}$ profiles (see Fig. 4) and the following equation:

$$
\% \text { Remaining activity }=\frac{\text { Uptake }_{\text {Oatp }}^{\text {Rif(+) }}-\text { Uptake }_{\text {mock }}}{\operatorname{Uptake}_{\text {Oatp }}^{\text {Rif }(-)}-\text { Uptake }_{\text {mock }}}
$$

where Uptake $\mathrm{Oatp}_{\text {Oatp }}^{\mathrm{Ri}(-)}$ is the RSV uptake into the Oatp-expressing cells in the absence of rifampin and was fixed as $100 \%$. The Uptake mock $_{\text {is }}$ is the RSV uptake (\% of max) into the mock-transfected cells, and Uptake $e_{\text {Oatp }}^{\text {Rif }(+)}$ is the RSV uptake (\% of max) into the Oatp-expressing cells in the presence of $9.4 \mu \mathrm{M}$ rifampin.

Statistical Analysis. The experimental data are shown as the mean \pm S.D. The parameters estimated from Phoenix are shown as the mean \pm S.E. Statistically significant differences between the various groups were determined by the Welch's $t$ test (corrected for multiple comparisons).

\section{Results}

Time-Dependent Uptake of RSV or OLM into Ntcp- or OatpExpressing Cells. We first evaluated TCA or E17 $\beta \mathrm{G}$ uptake into Oatp- or Ntcp-expressing cells and confirmed that these cell lines are functional (Supplemental Fig. 1). Consistent with previous reports (Ho et al., 2006; Ishida et al., 2018), RSV was transported by Oatp1a1, 1a4, and 1b2, but not by Ntcp (Fig. 1). RSV uptake by Oatp1a1 approached a plateau by 15 seconds, whereas that by Oatp1a4 and $1 \mathrm{~b} 2$ was linear for at least 15 seconds. In contrast, OLM was transported by only Oatp1b2, and this uptake was linear up to at least 30 seconds (Fig. 1). Therefore, in subsequent experiments we evaluated the 5-second (Oatp1a1) and 15-second (Oatp1a4 and 1b2) uptake of RSV or OLM (Oatp1b2 only).

Estimation of Kinetics of Uptake of RSV or OLM by CHOOatp1a1, HEK293-Oatp1a4, HEK293-Oatp1b2 Cells. As expected, the uptake of $\left[{ }^{3} \mathrm{H}\right]-\mathrm{RSV}$ and $\left[{ }^{3} \mathrm{H}\right]-\mathrm{OLM}$ was decreased with increasing unlabeled RSV and OLM concentration (representative experiments are shown in Fig. 2). Oatpla1 transported RSV with higher affinity than Oapt1a4 (Table 1). In addition, Oatp1b2 transported RSV with higher affinity than OLM (Table 1). The $K_{\mathrm{m}}$ values obtained informed the RSV and OLM concentrations used in the inhibition experiments described herein. Also, the RSV $K_{\mathrm{m}}$ and $V_{\max }$ values were used to predict the in vivo inhibition of the sinusoidal uptake clearance of the drug by rifampin.

Identification of Selective Inhibitors of RSV, E17ßG, or OLM Uptake into Oatp-Expressing Cells. In an initial screen conducted at a low $(10 \mu \mathrm{M})$ and high $(100 \mu \mathrm{M})$ inhibitor concentrations, ibuprofen $(100 \mu \mathrm{M})$ and OLM $(100 \mu \mathrm{M})$ appeared to be selective inhibitors of Oatp1b2-mediated RSV uptake (Fig. 3A). On the other hand, digoxin $(10 \mu \mathrm{M})$ and quinine $(10 \mu \mathrm{M})$ appeared to be selective inhibitors of Oatp1a4-mediated RSV uptake. Rifampin $(10 \mu \mathrm{M})$ inhibited Oatp1a4 and $1 \mathrm{~b} 2$ only whereas rifamycin SV $(10 \mu \mathrm{M})$ inhibited only Oatp1a1and 1b2-mediated RSV uptake. Glyburide inhibited all three rat hepatic Oatps (Fig. 3A). BSP also inhibited all three rat hepatic Oatps, but $100 \mu \mathrm{M}$ BSP did not completely inhibit all rat hepatic Oatps (Fig. 3A). A similar trend was observed of inhibition of Oatp1a1- and 1a4-mediated E17 $\beta \mathrm{G}$ uptake (Fig. 3B) or of Oatp1b2-mediated OLM uptake (Fig. 3C), except the E17 $\beta \mathrm{G}$, but not RSV, uptake by Oatp1a1 was inhibited by $10 \mu \mathrm{M}$ quinine (Fig. 3, A and B). 
A
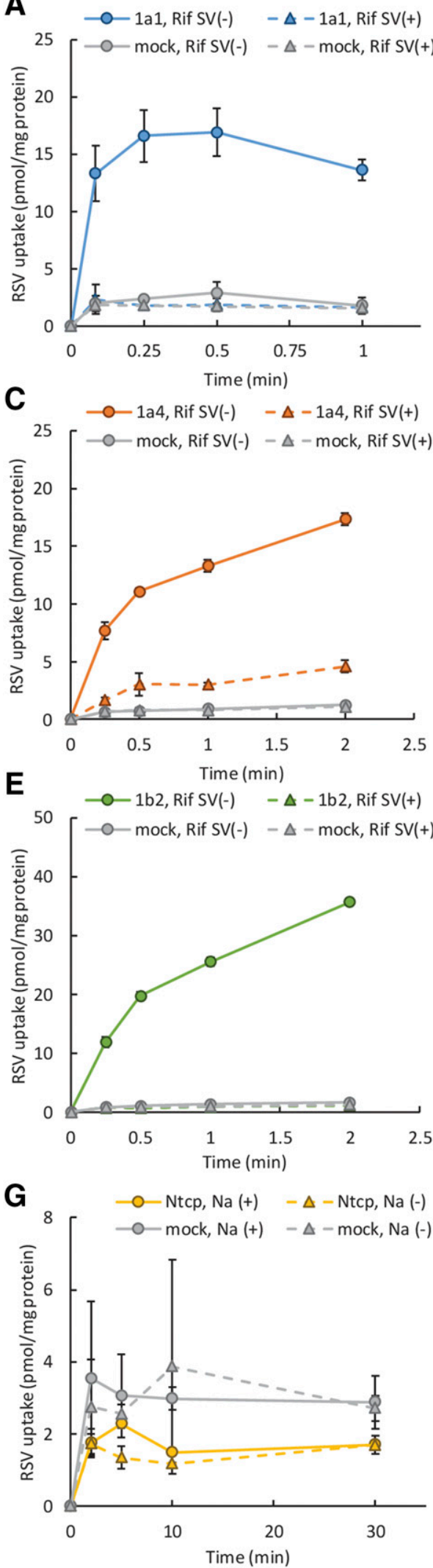

B
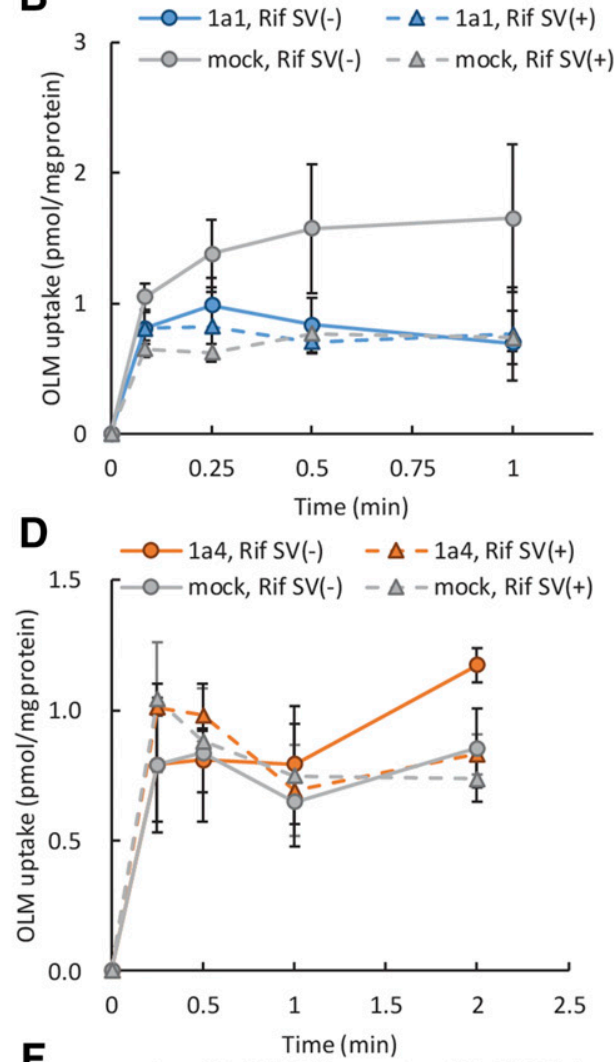

$\mathbf{F}$
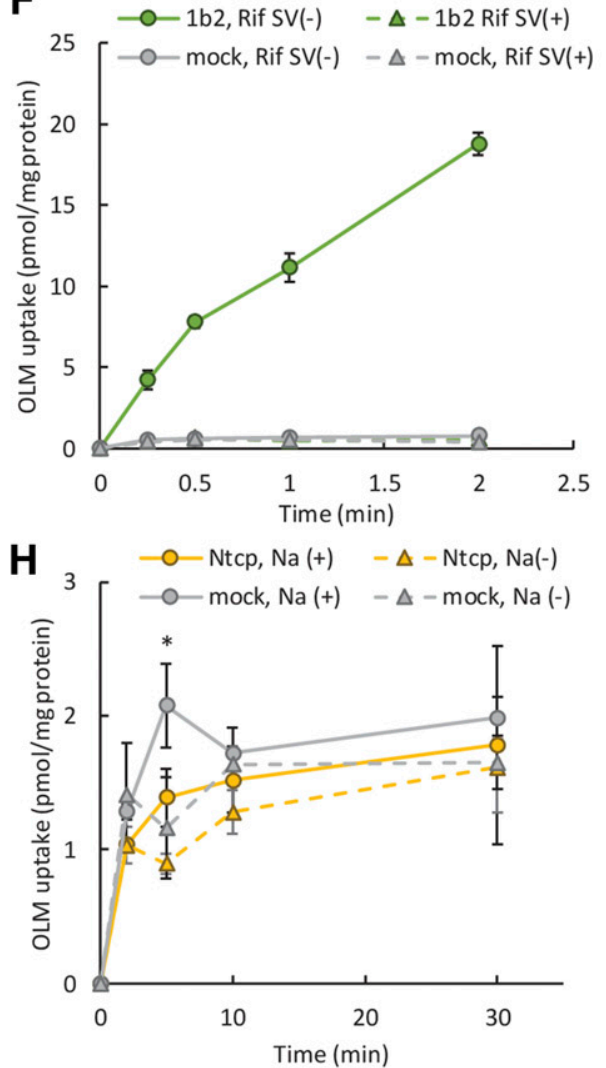

Fig. 1. Time course of RSV or OLM uptake into Oatp- or Ntcp-expressing cell lines. The uptake of drugs into Oatp-expressing cells (A-F) was determined in the presence and absence of $100 \mu \mathrm{M}$ rifamycin SV (Rif SV). The uptake of RSV (G) or OLM $(\mathrm{H})$ into $\mathrm{CHO}-\mathrm{Ntcp}$ cell lines was evaluated in the presence and absence of extracellular $\mathrm{Na}^{+}$. RSV was transported by Oatpla1 (A), 1a4 (C), and 1 b2 (E) but not by Ntcp (G). In contrast, OLM was transported by only Oatp1b2 (F) but not by Oatp1a1 (B), 1a4 (D) or Ntcp (H). Note the different $y$-axis scale in each panel. The data represent the mean \pm S.D. of triplicates.
Determination of $\mathbf{I C}_{\mathbf{5 0}}$ of Inhibitors of Rat Hepatic Oatp. Based on the previous data and to confirm that these compounds were selective inhibitors of the indicated Oatp, we determined their $\mathrm{IC}_{50}$ values using
RSV and OLM as substrates. (Fig. 4; Supplemental Fig. 2). While $100 \mu \mathrm{M}$ rifampin completely inhibited Oatp1a4 and $1 \mathrm{~b} 2$, at this concentration it also significantly inhibited Oatpla1 (by about 50\%) 
A

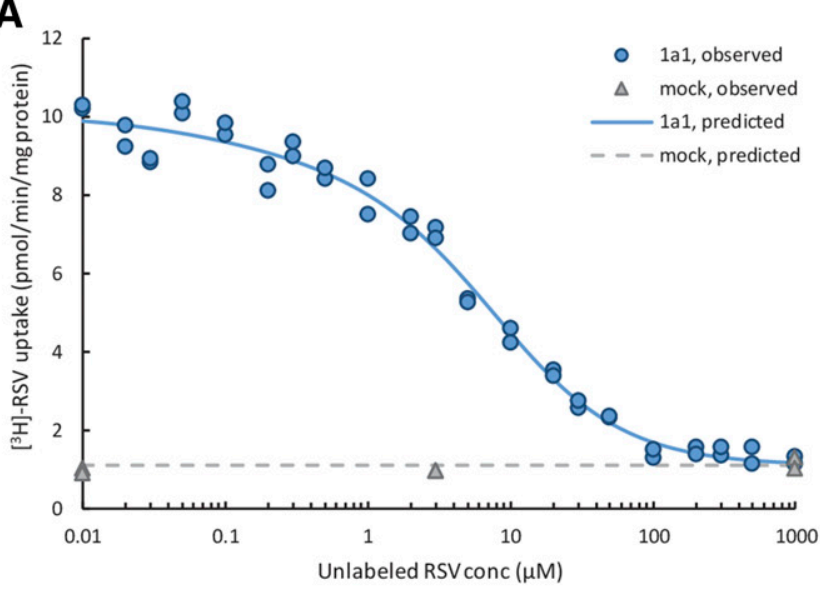

C

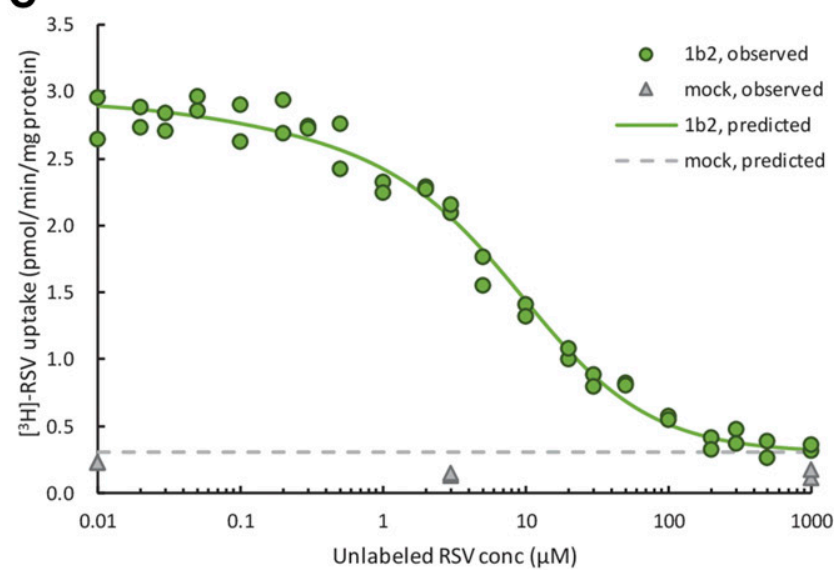

B

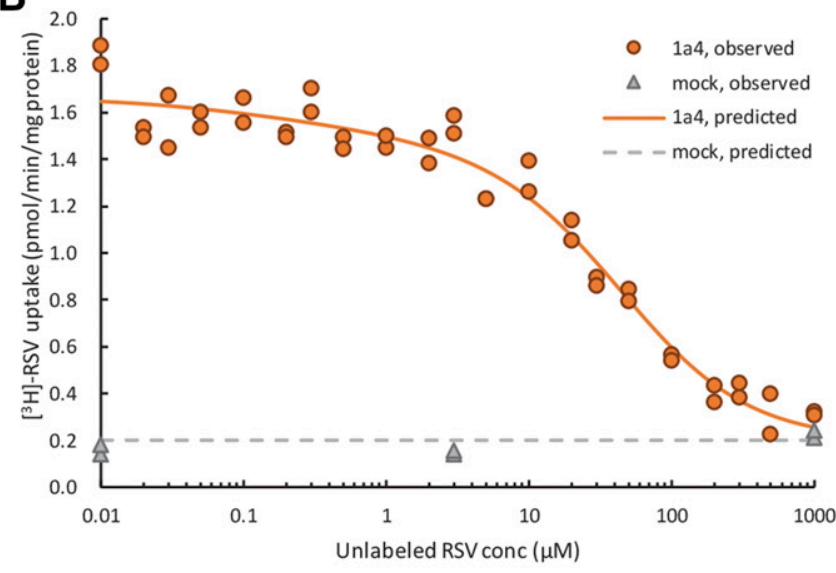

D

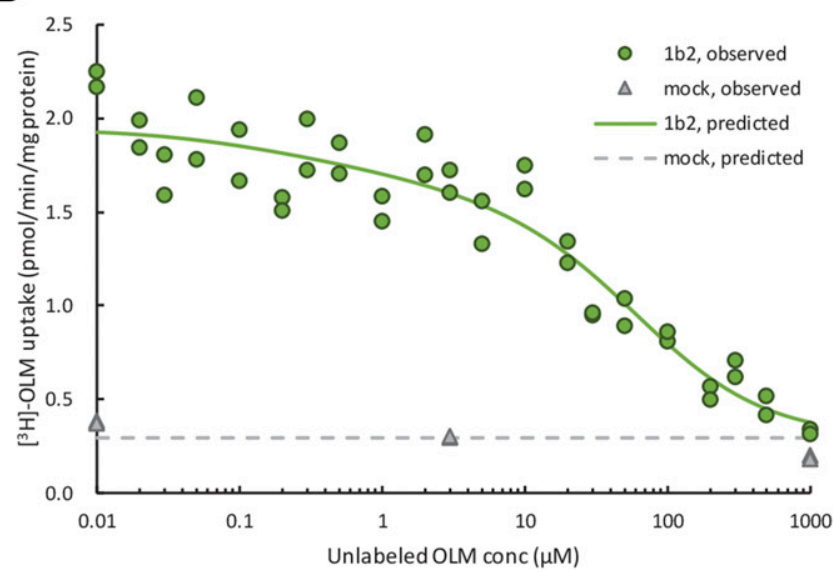

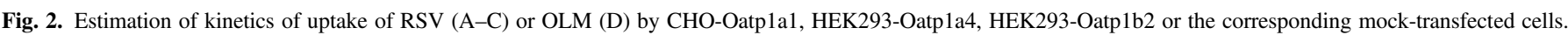

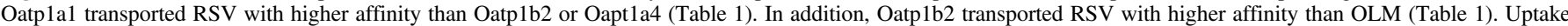

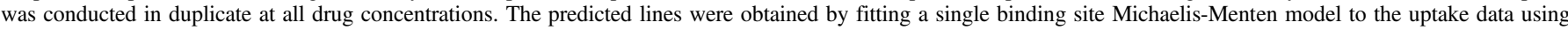
Phoenix.

(Fig. 4, A-D). Rifamycin SV (1 $\mu \mathrm{M})$ completely inhibited Oatp1b2 but did not inhibit Oatp1a1 or 1a4 (Fig. 4, E-H). Digoxin $(100 \mu \mathrm{M})$ completely inhibited Oatp1a4 but not Oatp1a1 or 1 b2 (Fig. 4, I-L). Ibuprofen $(1000 \mu \mathrm{M})$ did not inhibit Oatpla4 but inhibited Oatpla1 and Oatp1b2 (Supplemental Fig. 2, A-D). Quinine inhibited all Oatps when the concentration of the drug was greater than $20 \mu \mathrm{M}$ (Supplemental Fig. 2, E-H). Although OLM is a selective substrate of Oatp1b2 (Fig. 1), at $1000 \mu \mathrm{M}$ it completely inhibited Oatp1b2 and partially inhibited Oatp1a1 but not Oatp1a4 (Supplemental Fig. 2, I-K). BSP inhibited
Oatp1a4 less potently than Oatp1a1 or1b2, but inhibited all Oatps at $>300 \mu \mathrm{M}$ (Supplemental Fig. 2, L-O).

Prediction and Verification of the Magnitude of Inhibition of In Vivo Sinusoidal Uptake Clearance of RSV in the Presence of 9.4 $\boldsymbol{\mu M}$ Rifampin. We predicted the in vivo inhibition of the sinusoidal uptake clearance of RSV in rats using the intrinsic clearance $\left(V_{\max } / K_{\mathrm{m}}\right)$ and $K_{\mathrm{d}}$ (Table 2) and the abundance of Oatp protein in the rat liver and transfected cells (Wang et al., 2015; Ishida et al., 2018). Then we compared the predicted inhibition to our previous in vivo PET imaging

TABLE 1

Kinetics of uptake of rosuvastatin (RSV) or olmesartan acid (OLM) by the rat hepatic organic anion transporting polypeptides

Each experiment was conducted in duplicate, and parameters were estimated using Phoenix. The values are mean \pm S.D. of three independent experiments.

\begin{tabular}{|c|c|c|c|c|c|c|}
\hline \multirow{2}{*}{ Oatp } & \multirow{2}{*}{ Substrate } & $K_{\mathrm{m}}$ & $V_{\max }$ & \multirow{2}{*}{$\mathrm{H}$} & $K_{\mathrm{d}}$ & $\mathrm{CL}_{\text {int }}\left(V_{\max } / K_{\mathrm{m}}\right)$ \\
\hline & & $\mu M$ & $\mathrm{pmol} / \mathrm{min}$ per mg protein & & \multicolumn{2}{|c|}{$\mu \mathrm{l} / \mathrm{min}$ per mg protein } \\
\hline 1a1 & RSV & $9.61 \pm 3.97$ & $3594 \pm 1152$ & $0.97 \pm 0.02$ & $56.8 \pm 19.4$ & $386 \pm 53$ \\
\hline $1 \mathrm{a} 4$ & RSV & $67.2 \pm 17.1$ & $3077 \pm 67$ & $0.98 \pm 0.01$ & $7.56 \pm 2.21$ & $47.8 \pm 11.5$ \\
\hline \multirow[t]{2}{*}{$1 \mathrm{~b} 2$} & RSV & $28.1 \pm 14.8$ & $2242 \pm 970$ & $0.93 \pm 0.03$ & $10.1 \pm 4.9$ & $86.7 \pm 21.5$ \\
\hline & OLM & $72.8 \pm 23.9$ & $2169 \pm 485$ & $0.94 \pm 0.01$ & $6.18 \pm 1.36$ & $30.6 \pm 3.6$ \\
\hline
\end{tabular}

$\mathrm{CL}_{\text {int }}$, intrinsic clearance; $\mathrm{H}$, Hill coefficient; $K_{\mathrm{d}}$, diffusion rate constant; $K_{\mathrm{m}}$, Michaelis-Menten constant; OLM, olmesartan acid; $V_{\max }$ maximum velocity of the uptake. 
A

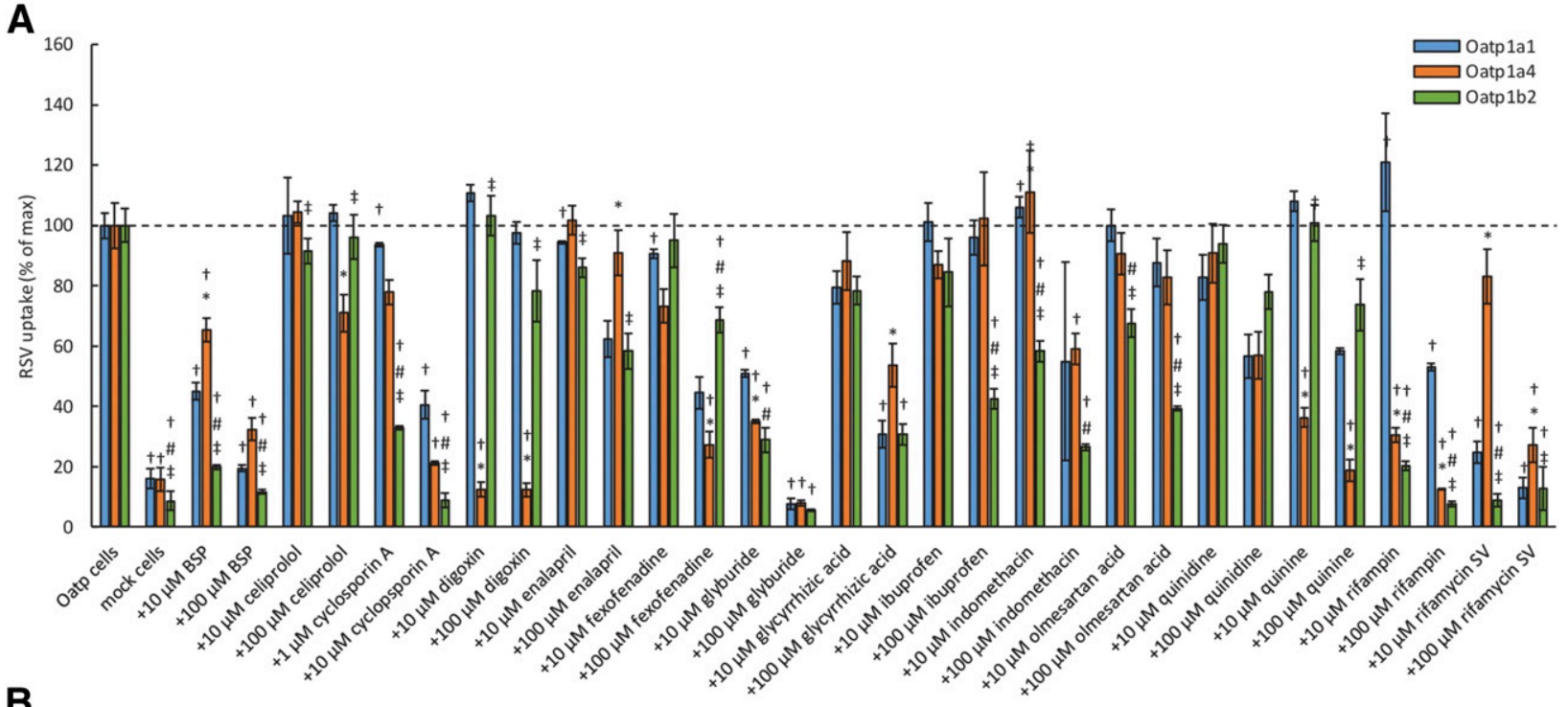

B
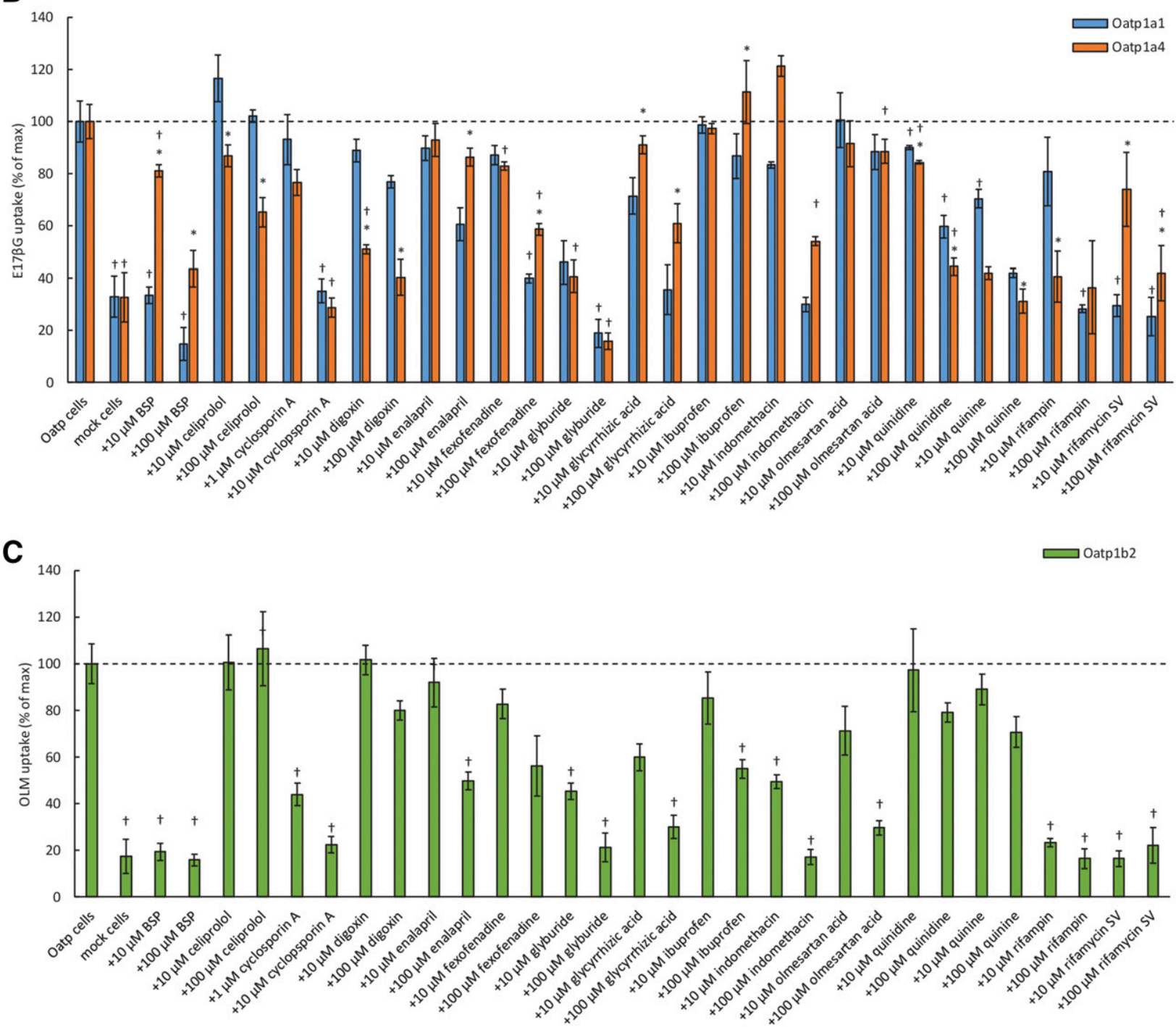

Fig. 3. Effect of various inhibitors (10 or $100 \mu \mathrm{M})$ on Oatp-mediated uptake of RSV (A), E17 $\beta \mathrm{G}$ (B), or OLM (C). Ibuprofen (100 $\mu \mathrm{M})$ and olmesartan acid (100 $\mu \mathrm{M})$ appeared to be selective inhibitors of Oatp1b2. On the other hand, digoxin $(10 \mu \mathrm{M})$ and quinine $(10 \mu \mathrm{M})$ appeared to be selective inhibitors of Oatp1a4. Rifampin $(10 \mu \mathrm{M})$ inhibited only Oatp1a4 and 1b2, whereas rifamycin SV $(10 \mu \mathrm{M})$ inhibited only Oatp1a1 and 1b2. BSP and glyburide inhibited all three rat hepatic Oatps. The data are mean \pm S.D. of triplicates. ${ }^{\dagger} P<0.05$; significantly different from the corresponding control (i.e., without the inhibitor). $* P<0.05$; significant difference between Oatp1a1 and Oatp1a4. ${ }^{\#} P<0.05$; significant difference between Oatp1a1 and Oatp1b2. ${ }^{{ }^{*}} P<0.05$; significant difference between Oatp1a4 and Oatp1b2. 
A

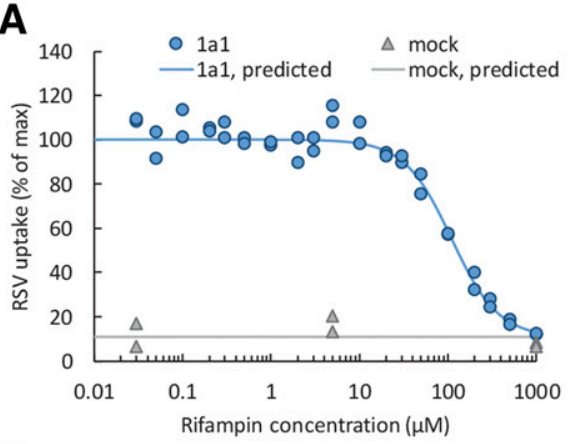

B

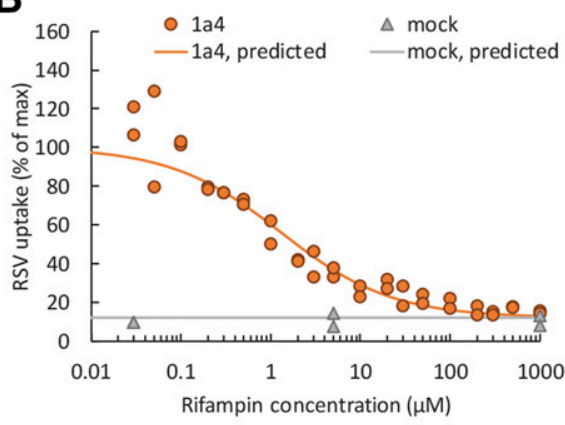

C

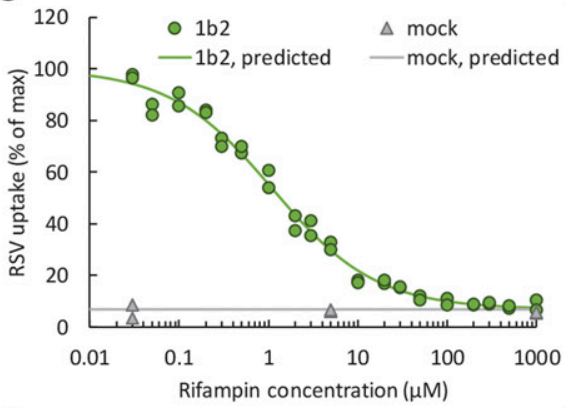

D

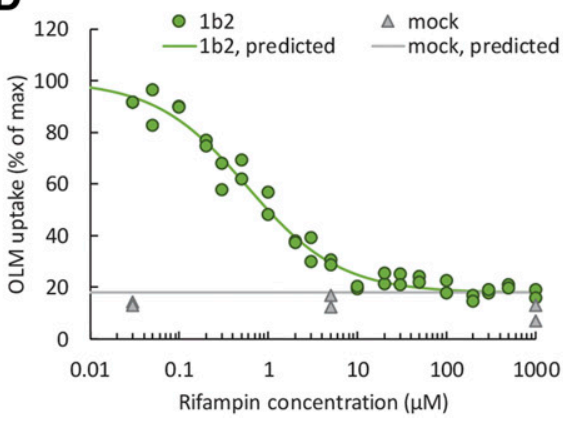

E

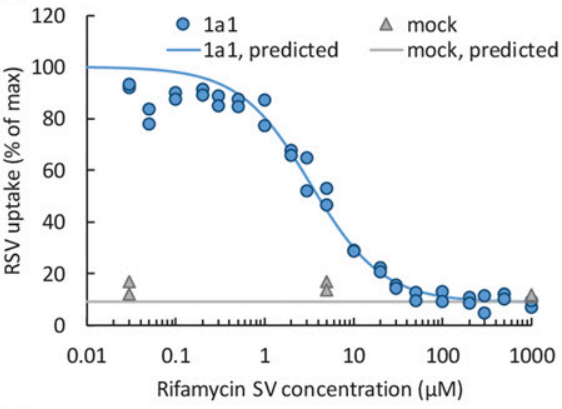

F

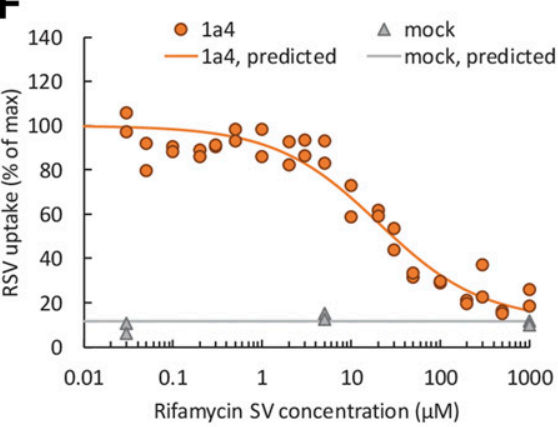

G

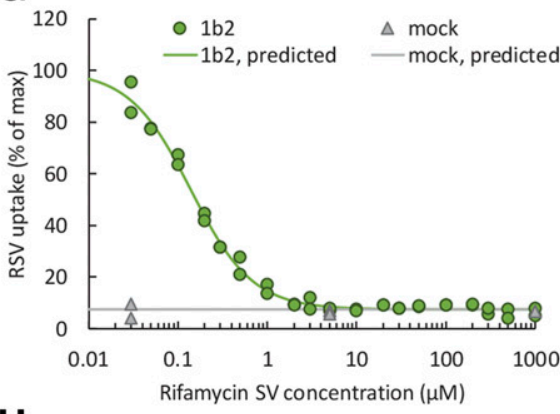

H

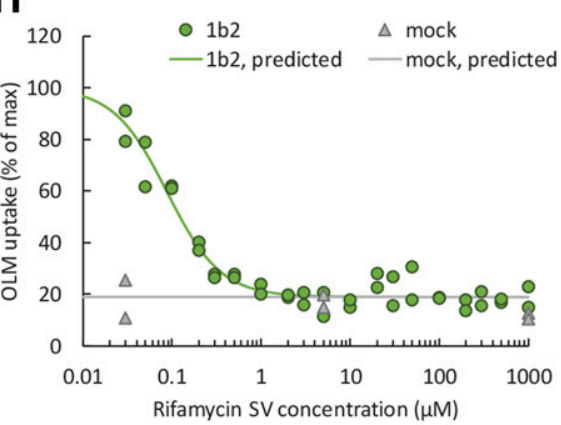

I

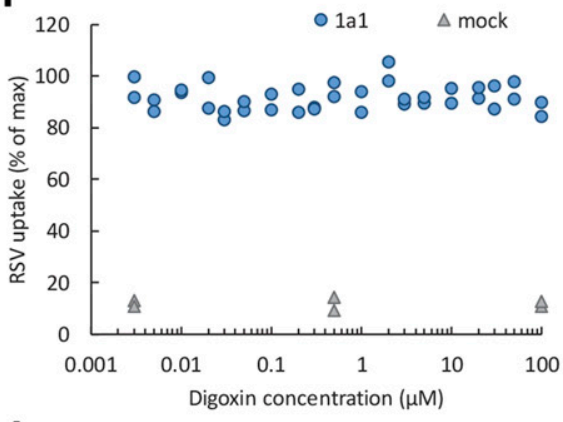

$\mathbf{J}$

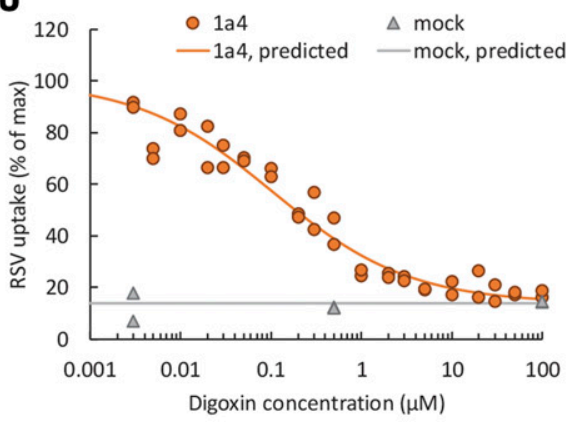

K

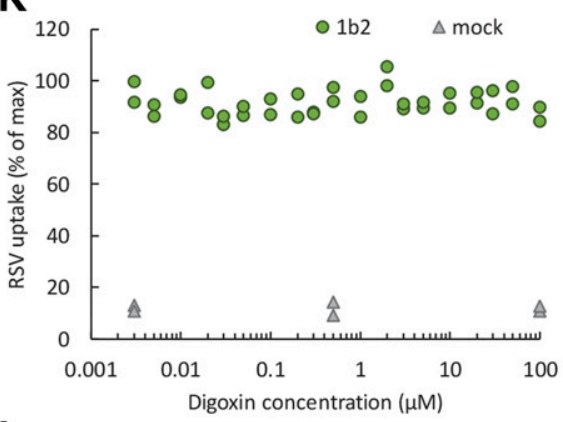

L

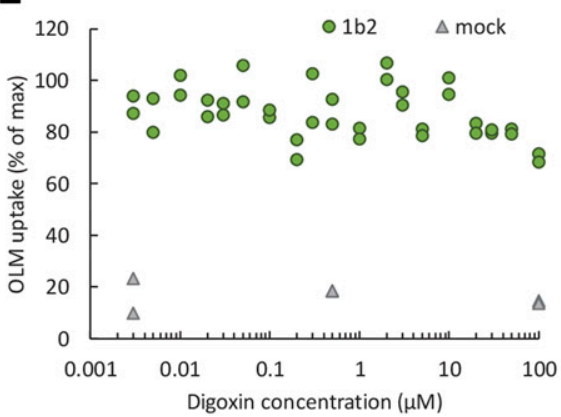

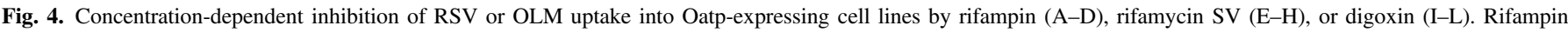

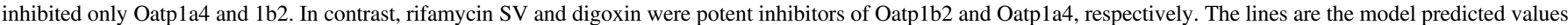
(Phoenix).

study (He et al., 2014). The magnitude of inhibition of sinusoidal uptake clearance of RSV by rifampin was well predicted (Table 3 ).

\section{Discussion}

Three Oatps, Oatp1a1, 1a4, and 1b2, are expressed in the rat liver, and their protein expression, as determined by quantitative targeted proteomics, is similar (Wang et al., 2015). Therefore, any pharmacokinetic studies or hepatic efficacy/toxicity of Oatp substrate drugs in the rat must include consideration of these transporters. Here, we estimated for the first time the transport kinetic parameters of RSV and OLM by three rat hepatic Oatps.

Because several OATPs/Oatps have been shown to have multiple binding sites (Westholm et al., 2009; Shirasaka et al., 2014), we first determined whether this was the case for the uptake of RSV or OLM by the three rat Oatps. To enhance our ability to discern multiple binding sites, our experimental design was deliberately rich in data points: 18-21 concentrations, in duplicate, densely scattered over a wide concentration range. Although we incorporated a second binding site (i.e., $K_{\mathrm{m}}$ and $\left.V_{\max }\right)$ into our model, the $95 \%$ confidence interval of these additional 
TABLE 2

$\mathrm{IC}_{50}$ and Hill coefficient of inhibitors of organic anion transporting polypeptide (Oatp)-mediated uptake of rosuvastatin (RSV) or olmesartan acid (OLM)

These parameters were estimated using the data in Fig. 4 and Supplemental Fig. 3. The data represent the mean \pm S.E. estimated by Phoenix.

\begin{tabular}{|c|c|c|c|c|c|c|c|c|c|}
\hline Oatp & Substrate & Parameter & BSP & Rifamycin SV & Quinine & Rifampin & Ibuprofen & Olmesartan & Digoxin \\
\hline \multirow[t]{2}{*}{ 1a1 } & RSV & $\mathrm{IC}_{50}(\mu \mathrm{M})$ & $3.00 \pm 0.25$ & $3.33 \pm 0.28$ & $72.8 \pm 6.5$ & $110 \pm 7$ & $485 \pm 52$ & $612 \pm 43$ & NI \\
\hline & & $\mathrm{H}$ & $1.12 \pm 0.06$ & $1.08 \pm 0.09$ & $0.826 \pm 0.057$ & $1.63 \pm 0.12$ & $1.23 \pm 0.19$ & $0.787 \pm 0.090$ & ND \\
\hline \multirow[t]{2}{*}{$1 \mathrm{a} 4$} & RSV & $\mathrm{IC}_{50}(\mu \mathrm{M})$ & $6.24 \pm 1.07$ & $20.5 \pm 2.9$ & $1.89 \pm 0.31$ & $1.31 \pm 0.23$ & NI & $\mathrm{NI}$ & $0.107 \pm 0.015$ \\
\hline & & $\mathrm{H}$ & $0.687 \pm 0.087$ & $0.746 \pm 0.074$ & $0.572 \pm 0.048$ & $0.704 \pm 0.074$ & ND & ND & $0.575 \pm 0.048$ \\
\hline \multirow[t]{2}{*}{$1 b 2$} & RSV & $\mathrm{IC}_{50}(\mu \mathrm{M})$ & $0.397 \pm 0.040$ & $0.140 \pm 0.007$ & $125 \pm 19$ & $1.12 \pm 0.68$ & $48.5 \pm 5.1$ & $23.1 \pm 4.0$ & NI \\
\hline & & $\mathrm{H}$ & $0.938 \pm 0.078$ & $1.26 \pm 0.06$ & $0.836 \pm 0.127$ & $0.752 \pm 0.032$ & $0.622 \pm 0.042$ & $0.930 \pm 0.107$ & ND \\
\hline \multirow[t]{2}{*}{$1 b 2$} & OLM & $\mathrm{IC}_{50}(\mu \mathrm{M})$ & $0.210 \pm 0.050$ & $0.088 \pm 0.009$ & $150 \pm 30$ & $0.583 \pm 0.053$ & $61.4 \pm 13.0$ & ND & $\mathrm{NI}$ \\
\hline & & $\mathrm{H}$ & $1.28 \pm 0.29$ & $1.44 \pm 0.18$ & $0.745 \pm 0.178$ & $0.835 \pm 0.063$ & $0.656 \pm 0.119$ & ND & ND \\
\hline
\end{tabular}

H, Hill coefficient; ND, not determined; NI, not inhibited by $100 \mu \mathrm{M}$ digoxin or $1000 \mu \mathrm{M}$.

parameters contained zero, so we deemed them not to be reliable (data not shown). Hence, our final kinetic model included one binding site for transport (to estimate the $K_{\mathrm{m}}, V_{\max }$, and Hill coefficient) as well as passive diffusion (to estimate the $K_{\mathrm{d}}$ ) (eqs. 1 and 2).

To determine the contribution of each OATP/Oatp in the uptake of drugs into hepatocytes or in vivo, it is important to conduct inhibition studies with selective transporters of each Oatp. However, to date such selective inhibitors have not been available as most drugs appear to be nonselective inhibitors of all Oatps. Here we found that rifamycin $\mathrm{SV}(1 \mu \mathrm{M})$ and digoxin $(20 \mu \mathrm{M})$ were selective and potent inhibitors of Oatp1b2 ( $\left.\mathrm{IC}_{50} 0.14 \mu \mathrm{M}\right)$ and Oatp1a4 ( $\left.\mathrm{IC}_{50} 0.1 \mu \mathrm{M}\right)$, respectively (Fig. 4). For the remaining inhibitors, although they were found to be potent inhibitors of some Oatps (e.g., $10 \mu \mathrm{M}$ quinine), when they were tested at concentrations that completely inhibited those transporters, they partially inhibited other Oatps (Fig. 3). Thus, they were not considered selective. BSP $(>300 \mu \mathrm{M})$ and glyburide $(100 \mu \mathrm{M})$ nonselectively inhibited all the Oatps and were considered pan-Oatp inhibitors.

Although the $\mathrm{IC}_{50}$ value of an inhibitor is important, the ability of that inhibitor to inhibit the in vivo clearance of a victim drug mediated by an Oatp(s) depends on the plasma concentration of the inhibitor achieved relative to its $\mathrm{IC}_{50}$. Thus, although some of the inhibitors studied, at first sight, may not appear to be potent inhibitors of Oatps, if the unbound portal vein plasma concentrations of the inhibitor (at the doses used) exceeds its IC $_{50}$ value for an Oatp, the inhibitor will inhibit that hepatic Oatp in vivo. In addition, with the inhibitors tested, substrate-dependent

\section{TABLE 3}

Excellent agreement between the observed and predicted magnitude of inhibition by rifampin of the in vivo rosuvastatin sinusoidal uptake clearance in the rat as measured by PET imaging

\begin{tabular}{|c|c|c|}
\hline & \multicolumn{2}{|c|}{ Sinusoidal Uptake Clearance } \\
\hline & Observed $^{a}$ & Predicted $^{b}$ \\
\hline & \multicolumn{2}{|c|}{$\mathrm{ml} / \mathrm{min}$ per $\mathrm{kg}$ body weight } \\
\hline Rifampin (-) & $70.95 \pm 2.88$ & $80.44 \pm 13.05$ \\
\hline Rifampin (+) & $37.28 \pm 1.48$ & $45.69 \pm 7.95$ \\
\hline$\%$ Rifampin (-) & $52.5 \%$ & $56.8 \%$ \\
\hline
\end{tabular}

${ }^{a}$ Observed data are from our previous positron emission tomography (PET) imaging study where the mean unbound concentration of rifampin after administration $(40 \mathrm{mg} / \mathrm{kg}$ intravenous bolus plus $1.85 \mathrm{mg} / \mathrm{min}$ per kilogram intravenous infusion) was $9.4 \mu \mathrm{M}$ (He et al., 2014).

${ }^{b}$ The in vivo predicted sinusoidal uptake clearance in the absence of rifampin was estimated by Michaelis-Menten constant $\left(K_{\mathrm{m}}\right)$, maximum velocity of the uptake $\left(V_{\max }\right)$, and diffusion rate constant $\left(K_{\mathrm{d}}\right)$ (Table 1$)$ and the abundance of organic anion transporting polypeptide (Oatp) protein as reported previously (Ishida et al., 2018). The in vivo predicted sinusoidal uptake clearance in the presence of rifampin was calculated by eq. 2 , and the $\%$ remaining activity of each Oatp in the presence of $9.4 \mu \mathrm{M}$ rifampin $(94.8 \%, 10.5 \%$, and $18.9 \%$ for Oatp1a1, 1a4, and $1 \mathrm{~b} 2$, respectively) was obtained from Fig. $4, \mathrm{~A}-\mathrm{C}$. inhibition of RSV, OLM, and E17 $\beta$ G was not observed (Figs. 3 and 4; Supplemental Fig. 2; Table 2).

Previous Oatp inhibition studies have focused on only one or two rat hepatic Oatps (Fattinger et al., 2000; Shitara et al., 2002; Ismair et al., 2003). Our findings are generally consistent with these previous reports (Fattinger et al., 2000; Shitara et al., 2002) but expand on these reports by including studies on Oatp1b2. However, we did observe some differences between the present study and a previous report by Shitara et al. (2002). Shitara et al. (2002) evaluated the inhibitory effect of many compounds on Oatp1a1- and Oatp1a4-mediated uptake of E17 $\beta \mathrm{G}$ and digoxin, respectively. Consistent with our data, Oatp1a1- and 1a4 were not inhibited by $10 \mu \mathrm{M}$ indomethacin; however, they found that Oatp1a1, but not Oatp1a4, was inhibited when the indomethacin concentration was increased to $100 \mu \mathrm{M}$. In the present study, we found that $100 \mu \mathrm{M}$ indomethacin inhibited all three rat hepatic Oatps (Fig. 3). Unlike us, they found that quinidine $(100 \mu \mathrm{M})$ inhibited Oatpla1 but not Oatp1a4 activity, but their $\mathrm{IC}_{50}$ profiles of inhibition by quinidine showed that $\mathrm{IC}_{50}$ values of quinidine for Oatp1a1 and 1a4 are similar. (Shitara et al., 2002). We found that quinidine $(100 \mu \mathrm{M})$ slightly inhibited both Oatp1a1 and 1a4 activity but not Oatp1b2 activity (Fig. 3 ). In all cases, we observed inhibitory effect of these drugs at lower concentrations than previously reported. One reason for this difference may be that we preincubated the cells with the inhibitors, and the previous investigators did not.

In the present study, we were successful in identifying selective inhibitors of Oatp1b2 and 1a4 but not Oatp1a1. Therefore, we propose the following experimental design to distinguish Ntcp-, Oatp-, and passive diffusion-mediated uptake of the drug into rat hepatocytes (in vitro and potentially in vivo) (Fig. 5). As usual, the contribution of Ntcpdependent uptake can be estimated by the difference in the drug uptake in the presence and absence of extracellular $\mathrm{Na}^{+}$. Because $1 \mu \mathrm{M}$ rifamycin SV and $20 \mu \mathrm{M}$ digoxin selectively and completely inhibited Oatp1b2 and Oatp1a4, respectively (Fig. 4), the contribution of Oatp1b2 and $1 \mathrm{a} 4$ can be estimated by using the selective inhibitor $1 \mu \mathrm{M}$ rifamycin $\mathrm{SV}$ and $20 \mu \mathrm{M}$ digoxin, respectively, under the extracellular $\mathrm{Na}^{+}$-free condition (Figs. 4 and 5; Table 2). Glyburide (or BSP) is a pan inhibitor of rat hepatic Oatps (Fig. 3); therefore, the passive diffusion-mediated uptake of the drug can be estimated in the presence of $100 \mu \mathrm{M}$ glyburide (or $300 \mu \mathrm{M}$ BSP) under the $\mathrm{Na}^{+}$-free condition.

Although, we did not identify a selective inhibitor of Oatp1a1, its contribution can be obtained by taking the difference in drug uptake in the presence of digoxin $(20 \mu \mathrm{M})$ plus rifamycin $\mathrm{SV}(1 \mu \mathrm{M})$ and glyburide $(100 \mu \mathrm{M})$. This strategy assumes that these inhibitors will not inhibit other transporters/metabolizing enzymes that may also transport/metabolize the drug of interest.

To predict the magnitude of the transporter-mediated drug-drug interactions (DDI), the ft by a particular transporter needs to be estimated 


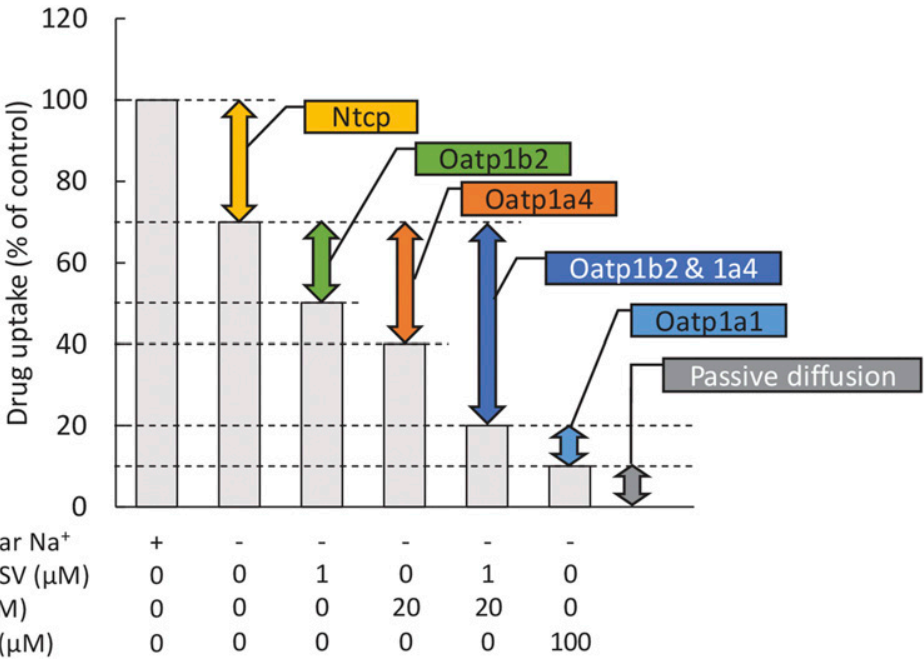

Fig. 5. Proposed experimental design to distinguish Ntcp-, Oatp-, and passive diffusion-mediated uptake of drugs by rat hepatic Oatps.

$\begin{array}{llllccc}\text { Extracellular } \mathrm{Na}^{+} & + & - & - & - & - & - \\ \text {Rifamycin } \mathrm{SV}(\mu \mathrm{M}) & 0 & 0 & 1 & 0 & 1 & 0 \\ \text { Digoxin }(\mu \mathrm{M}) & 0 & 0 & 0 & 20 & 20 & 0 \\ \text { Glyburide }(\mu \mathrm{M}) & 0 & 0 & 0 & 0 & 0 & 100\end{array}$

Endres CJ, Moss AM, Ke B, Govindarajan R, Choi DS, Messing RO, and Unadkat JD (2009) The role of the equilibrative nucleoside transporter 1 (ENT1) in transport and metabolism of ribavirin by human and wild-type or Ent $1^{-/-}$mouse erythrocytes. J Pharmacol Exp Ther 329:387-398.

Fattinger K, Cattori V, Hagenbuch B, Meier PJ, and Stieger B (2000) Rifamycin SV and rifampicin exhibit differential inhibition of the hepatic rat organic anion transporting polypeptides, Oatp1 and Oatp2. Hepatology 32:82-86.

He J, Yu Y, Prasad B, Link J, Miyaoka RS, Chen X, and Unadkat JD (2014) PET imaging of Oatpmediated hepatobiliary transport of $\left[{ }^{11} \mathrm{C}\right]$ rosuvastatin in the rat. Mol Pharm 11:2745-2754.

Ho RH, Tirona RG, Leake BF, Glaeser H, Lee W, Lemke CJ, Wang Y, and Kim RB (2006) Drug and bile acid transporters in rosuvastatin hepatic uptake: function, expression, and pharmacogenetics. Gastroenterology 130:1793-1806

Hsiao P and Unadkat JD (2012) P-glycoprotein-based loperamide-cyclosporine drug interaction at the rat blood-brain barrier: prediction from in vitro studies and extrapolation to humans. $M o$ Pharm 9:629-633.

Hsiao P and Unadkat JD (2014) Predicting the outer boundaries of P-glycoprotein (P-gp)-based drug interactions at the human blood-brain barrier based on rat studies. Mol Pharm 11:436-444. Ishida K, Ullah M, Tóth B, Juhasz V, and Unadkat JD (2018) Successful prediction of in vivo hepatobiliary clearances and hepatic concentrations of rosuvastatin using sandwich-cultured rat hepatocytes, transporter-expressing cell lines, and quantitative proteomics. Drug Metab Dispos 46:66-74.

Ismair MG, Stanca C, Ha HR, Renner EL, Meier PJ, and Kullak-Ublick GA (2003) Interactions of glycyrrhizin with organic anion transporting polypeptides of rat and human liver. Hepatol Res 26:343-347.

Li R, Barton HA, and Varma MV (2014) Prediction of pharmacokinetics and drug-drug interactions when hepatic transporters are involved. Clin Pharmacokinet 53:659-678.

Malo C and Berteloot A (1991) Analysis of kinetic data in transport studies: new insights from kinetic studies of $\mathrm{Na}^{+}$-D-glucose cotransport in human intestinal brush-border membrane vesicles using a fast sampling, rapid filtration apparatus. J Membr Biol 122:127-141.

Prasad B and Unadkat JD (2015) The concept of fraction of drug transported (ft ) with special emphasis on BBB efflux of CNS and antiretroviral drugs. Clin Pharmacol Ther 97:320-323.

Shirasaka Y, Mori T, Murata Y, Nakanishi T, and Tamai I (2014) Substrate- and dose-dependent drug interactions with grapefruit juice caused by multiple binding sites on OATP2B1. Pharm Res 31:2035-2043.

Shitara Y, Sugiyama D, Kusuhara H, Kato Y, Abe T, Meier PJ, Itoh T, and Sugiyama Y (2002) Comparative inhibitory effects of different compounds on rat oatpl (slc21a1)- and Oatp2 (Slc21a5)-mediated transport. Pharm Res 19:147-153.

Wang L, Prasad B, Salphati L, Chu X, Gupta A, Hop CE, Evers R, and Unadkat JD (2015) Interspecies variability in expression of hepatobiliary transporters across human, dog, monkey, and rat as determined by quantitative proteomics. Drug Metab Dispos 43:367-374.

Westholm DE, Salo DR, Viken KJ, Rumbley JN, and Anderson GW (2009) The blood-brain barrier thyroxine transporter organic anion-transporting polypeptide $1 \mathrm{c} 1$ displays atypical transport kinetics. Endocrinology 150:5153-5162.

Address correspondence to: Dr. Jashvant D. Unadkat, Department of Pharmaceutics, Box 357610, University of Washington, Seattle, WA 98195. E-mail: jash@u. washington.edu

\section{References}

Chenu C and Berteloot A (1993) Allosterism and $\mathrm{Na}^{+}$-D-glucose cotransport kinetics in rabbit jejunal vesicles: compatibility with mixed positive and negative cooperativities in a homodimeric or tetrameric structure and experimental evidence for only one transport protein involved. J Membr Biol 132:95-113. 